\title{
Barriers and Facilitators of Disclosing Domestic Violence to the UK Health Service
}

\author{
Rebecca L. Heron ${ }^{1,2,3}$ (D) Maarten C. Eisma ${ }^{2} \cdot$ Kevin Browne $^{3}$ \\ Accepted: 14 December 2020 / Published online: 4 January 2021 \\ (C) The Author(s) 2021, corrected publication 2021
}

\begin{abstract}
Domestic violence victims frequently visit health care facilities yet rarely disclose, so it is important to understand what factors are barriers and facilitators of disclosure. UK-based qualitative investigations into barriers and facilitators of disclosure in health care settings have suffered from a limited focus on ethnic minority women. Therefore, the aim of this study was to explore victims' perceptions and experiences of disclosing to health care services and to identify barriers and facilitators of disclosure within an ethnically diverse UK sample. Semi-structured interviews were administered among 29 British (8 ethnic minority) female victims. Content analysis demonstrated that barriers to disclosure were; emotional (e.g., fear, embarrassment/shame and self-blame), physical (e.g., partner's physical presence, controlling behavior, and manipulation of professionals) and organizational (e.g., appropriateness of setting and time for disclosure). Additional problems for ethnic minority women were language difficulties and religious practices. Facilitators to disclosure were interpersonal relations, safety, and validation from health care professionals. Barriers and facilitators of disclosure in health care services are diverse and some are specific to minority ethnic groups. Health care professionals should receive awareness and skills training to establish a positive, validating, and safe environment for victim disclosure.
\end{abstract}

Keywords Intimate partner violence $\cdot$ IPV $\cdot$ Domestic abuse $\cdot$ Battered women $\cdot$ Disclosure $\cdot$ Support seeking $\cdot$ Health care professionals $\cdot$ Nursing

Domestic violence is a serious worldwide societal and public health issue (World Health Organization 2013). According to the Department of Health (2017), one in four women and one in six men in England and Wales will suffer domestic violence in some form. From March 2013, the UK definition of domestic violence is: "Any incident or pattern of incidents of

Rebecca L. Heron

HeronR@uhv.edu

Maarten C. Eisma

m.c.eisma@rug.nl

Kevin Browne

kevin.browne@nottingham.ac.uk

1 Present address: Department of Arts \& Sciences, University of Houston-Victoria, 3007 N. Ben Wilson, Victoria, TX 77901, USA

2 Department of Behavioural and Social Sciences, University of Groningen, Groningen, Netherlands

3 Department of Medicine \& Health Sciences, University of Nottingham, Nottingham, UK controlling, coercive or threatening behaviour, violence or abuse between those aged 16 or over who are or have been intimate partners or family members regardless of gender or sexuality." This can encompass psychological, physical, sexual, financial and emotional abuse" (Home Office, CrossGovernment definition of domestic violence: a consultation, September 2012, p19).

Domestic violence has negative health outcomes for both male and female victims (Chibber et al. 2016; Hester et al. 2015). However, female victims of domestic violence (compared to male victims) experience more frequent and serious injuries (World Health Organization, 2013) and are found to be more at risk of repeated abuse (Walby et al. 2015). Therefore, this study will focus exclusively on female victims of intimate partner violence.

Female victims of domestic violence compared to their non-abused counterparts have been found to visit the health care service much more frequently (Rivara et al. 2007). Victims suffer adverse and long-term physical and psychological health problems (Garcia-Moreno et al. 2013). 
When female abuse victims disclose to a professional, they can be directed to specialist services where they can develop a safety plan and can receive more information about resources for abuse victims. Health care professionals can provide referrals or links to services such as advocacy and housing support, which can further benefit victims helping them to become independent, thereby improving their functioning and health, and limiting or stopping abuse (McFarlane et al. 2014; Spangaro et al., 2016b; for a review: Sprague et al. 2017). Despite the severe consequences of domestic violence, and benefits of disclosure, research shows that most victims choose not to disclose their experiences of abuse in formal and informal relationships (Evans and Feder 2014).

Within professional services, many victims' first or only point of contact is the health service (Othman et al. 2014). Previous research has shown that $45 \%$ of domestic violence victims who were killed by their abusive partners presented to a hospital 2 years prior to their death (Rivielo 2010). Victims of domestic abuse have a higher prevalence of using the health service than non-abused women (García-Moreno et al., 2015). As such, the health service has a unique potential to respond to domestic violence (Othman et al. 2014).

To use this potential, health care professionals are advised to conduct routine screening for domestic violence within the UK (National Institute for Health and Care Excellence 2014) and national and international guidelines have been developed on how health care professionals should respond to victims of domestic violence (National Institute for Health and Care Excellence 2014; World Health Organisation 2013).

Previous studies however have shown that despite these guidelines, doctors and nurses rarely ask about intimate partner violence and often fail to identify the signs of domestic abuse (Correa et al. 2020; McGarry and Nairn 2015). Health care professionals' hesitancy to ask about domestic abuse (Sundborg et al. 2017) has resulted in them providing inadequate care (Bradbury-Jones and Broadhurst 2015). In the UK, qualitative studies among mental health professionals showed that many did not feel competent or confident to respond to domestic violence in their practice (Rose et al. 2011) and health care professionals felt incapable and uncomfortable discussing domestic abuse (Taylor et al. 2013). These findings are complemented by other studies showing that only a small number of domestic violence victims are identified (Chapman and Monk 2015). Health care professionals may thus not be adequately responding to domestic violence victims. Inadequate responses by health care professionals may be explained by a lack of knowledge due to a lack of formal training (Rose et al. 2011) or receiving too little training on how to respond to domestic violence (Rimmer 2017). In part as a consequence, actions recommended in guidelines were not routinely carried out (Ramsay et al. 2012). Not surprisingly then, that domestic violence victims have reported low levels of satisfaction with the response received from the health care service to their disclosures (Trevillion et al. 2014).

In addition to organizational barriers, female domestic violence victims may also experience many personal barriers to disclosure, for example, fear, shame and embarrassment about abuse (Katiti et al. 2016), self-blame (Othman et al. 2014), and economic dependence on the abusive partner (Shanko et al. 2013). Furthermore, for ethnic minority victims, research has shown that they experience additional barriers to disclosing including problems with language and communication (FemiAjao et al. 2020) and fear of deportation due to their immigration status (Canadian Council for Refugees 2016).

In addition to the barriers that women perceive they are also likely to experience facilitators, which help them to disclose. For example, the quality of the relationship with the health care professional, such as listening ability, trust, and empathy have been found to help victims' disclosures (Spangaro et al. 2016a). Other facilitators for disclosure include the women being asked about abuse but not pressured into disclosing (Spangaro et al. 2016a).

\section{The Present Study}

Despite a growing interest in the topic, studies on domestic violence disclosure in the UK have predominantly focused on health care services employees (Hinsliff-Smith and McGarry 2017; Feder et al. 2009; McGarry 2016), and less attention has been devoted to understanding domestic violence victims' experiences. To gain insight into victims' perspectives on disclosure, qualitative research can be instrumental as it can provide an in-depth, holistic understanding of personal experiences and perspectives (Polit and Beck 2010). In the UK, there have been only a few qualitative studies of victim experiences of disclosure in health settings (e.g., Keeling and Fisher 2015; Salmon et al. 2015). Additionally, there have been even fewer UK studies exploring ethnic minority victim experiences of disclosing (Femi-Ajao et al. 2020) and several scholars have highlighted the importance of gaining a better understanding of domestic violence among ethnic minorities (Follingstad et al. 2012; Lacey et al. 2013). Therefore, we aimed to conduct a study within the UK exploring victims' experiences of disclosing to the health care service and we included both women from both ethnic majority and ethnic minority backgrounds in our qualitative study. Thereby we aimed to get a representative picture of the types of barriers and facilitators female victims experience when disclosing domestic violence to professionals working in the UK health care service (i.e., persons with a health-related qualification working in a health care setting). 


\section{Method}

\section{Participants}

Twenty-nine females participated in this study and were recruited from a domestic violence support organization based in the East Midlands of England. In order to obtain a heterogeneous and diverse sample of women who experienced domestic violence, participants were recruited through three different women's refuges (one of which was a Black and Ethnic Minority women's refuge) and a community domestic violence support service. Women who had experienced intimate partner abuse were identified by the managers of the refuges and the community domestic violence support service. The managers asked these women if they wanted to participate in the study, and they were explicitly instructed by the researchers not to use persuasion or emotional coercion to promote study involvement.

In total, 36 females were approached and 29 females (81\%) agreed to take part. Fifteen women were approached in the women's refuges, of which 12 women agreed to participate $(80 \%)$, and 21 women were approached through a community domestic violence support service, of which 17 agreed to participate $(81 \%)$. Reasons for not participating included not being able to obtain childcare, work or study commitments, and relocating to another safe address.

All of the women who participated identified themselves as having experienced physical and/or emotional abuse within the last 12 months from a male partner. The duration of violence was between 12 months and 33 years $(M=4.89$ years, $S D=5.86)$. The women varied in age, ethnicity and life experience. They were aged between 21 and 49 years $(M=26.7$, $S D=6.46)$. Twenty-one (72\%) of the participants were White British, four (14\%) of the participants were Black Caribbean, two (7\%) of the participants were Mixed Race, one (3\%) participant was Black British African, and one (3\%) participant was British Pakistani. Finally, three (10\%) of the participants had married their partners and $26(90 \%)$ had not.

\section{Ethical Considerations}

The World Health Organization (1999) highlights the importance of ethics when researching violence against women. It advocates that women's identities should be protected through confidentiality and women should be made to feel safe. This study abided by such ethics. Formal ethical approval was obtained from a School of Medicine ethical review board. Participants were informed about key aspects of the study (e.g. anonymity, data handling, voluntariness) and provided written informed consent. Measures were taken to maintain the women's safety, e.g., all interviews were conducted within a private setting, women's names were anonymized and any identifiable information was changed during transcription.
Additionally, the researchers also liaised with the refuge/ service providers to ensure that further support was made available to women after the interview should they need it.

\section{Study Design}

This study used a qualitative approach. One-on-one semistructured interviews were used rather than other qualitative methods (e.g., focus groups) as this would allow more detail as participants could speak more freely and provide more insight into their personal thoughts and feelings (Knodel 1993).

\section{Data Collection}

The interviewer contacted participants by telephone to arrange an appropriate time for the interview. Each woman when telephoned was asked if it was safe to talk. Interviews were conducted in a counselling room either at the refuge or at a community support office. The primary author conducted all the interviews. Most of the interview sessions lasted between one hour and one hour and a half. The interview schedule covered a range of topics, enquiring about the victim's disclosure to a social worker, police, friend/relative and health care service. However, the focus of this study was on victims' experiences of disclosure within the health care service. Among other things, we asked victims what their personal experiences of disclosure in health care settings are, whether they experienced barriers in disclosing to the health care service, and if they could provide any suggestions for how the health care service could make it easier for victims to disclose (See Online Supplement A for the full interview).

Participants' responses to the interview questions were written down manually on paper during the interview and interviews were not audio recorded. The organization whereby the women were recruited, did not give permission for the women's voices to be recorded, due to some of the women expressing discomfort with being recorded. Rubin and Rubin (1995) support that in some cases audio-recordings are not appropriate and so for this study we decided to only write the women's responses to ensure that participants felt as comfortable as possible to openly discuss their experiences. In order to ensure rigour when writing responses, the interviewer took pauses between questions, so that she could adequately write down the participants' answers. To ensure that writing down of participants' answers did not affect her ability to establish rapport with the participant, she avoided jargon in the interview and made eye contact or provided verbal reassurance when appropriate, for example, if a participant became upset. After the interview, participants were provided with a copy of the interview transcript (in note form) and were asked to provide feedback if they felt it had not accurately reflected what they had said. None of the participants 
indicated that any changes needed to be made to the transcripts. At the end of the interview participants were verbally debriefed and thanked for participating.

\section{Data Analysis}

Interviews were entered into a qualitative data analysis software, Nvivo 9 (QSR International, Cambridge, MA) and a content qualitative analysis approach was used to organize the data (Bowling 1997). This approach was deemed by the researchers to be appropriate as it is frequently employed to answer similar research questions. For example, content analysis has been used to answer questions such as "what reasons do people have or not have for not using a service?" (Ayres 2007). Content analysis is increasingly used in health research and as an approach has various advantages, for example, it allows data to be analysed qualitatively whilst still allowing for data to be quantified (Grbich 2007). Content analysis follows two main approaches to coding and analysing data (manifest and latent coding). "Manifest content refers to those elements that are physically present and countable while latent content refers to an interpretive reading of the symbolism underlying the physically presented data" (Berg 2004, p. 229). As recommended by Berg (2004), this study combined the approaches of manifest and latent coding.

Content analysis is a stepwise analytical process (Graneheim and Lundman 2004). The first step involved the primary researcher reading each of the transcripts and exploring the latent content and the overall tone of the transcripts. The researcher marked the passages that referred to victims' experiences and perceptions of disclosing to the health care service. The researcher then reread the transcripts and the manifest content approach was applied as certain words or phrases were noted and assigned to specific codes. The content analysis was partly deductive (top-down) as predefined categories were applied to textual units but also it was inductive as themes emerged from the textual data.

The pre-defined categories were: 1) barriers and 2) facilitators of disclosing to the health care service. After the primary researcher had coded the passages into meaningful categories (of subsets of barriers and facilitators of disclosure), a second researcher was approached to read the transcripts and to do the same to promote credibility of the analyses. Both researchers independently read the transcripts and came up with their own codes; the second researcher reviewed the primary researcher's codes against theirs and they agreed on the final codes together. Disagreements in coding were discussed and consensus was reached before deciding on the final codes.

Quotations were selected to support each of the categories and after discussions with the second researcher some of the categories were divided into sub-categories. Frequencies for each code were calculated and therefore each participant who was found to support a specific category of barriers and facilitators was tallied within that category. This allowed for the researchers to see how many participants overall had identified with a similar theme.

\section{Results}

Nearly all of the 29 female domestic violence victims in the sample $(n=28,97 \%)$ stated that they felt that all women should be routinely asked by their GP if they are experiencing domestic abuse. However, only 13 (45\%) of the women actually disclosed to a health care professional (who was either a doctor (eight), a nurse (two) or a midwife (three)). Only two of the women reported disclosing to two health care professionals for example, a midwife and a doctor and only one woman reported disclosing to all three (nurse, doctor and midwife). Sixteen (55\%) women stated that they felt that there were not enough leaflets on domestic violence in their GP's surgeries and 14 (48\%) participants stated that they felt that emotional abuse and physical abuse were treated differently by professionals, with emotional abuse being viewed as less serious. Most importantly, about two thirds (66\%) of the participants stated that they preferred disclosing to a woman.

\section{Barriers of Disclosing to the Health Care Service}

Three main categories or themes were found regarding the reasons why women find it difficult disclosing to the health care service. These categories included emotional barriers (69\%), partner-related barriers (38\%) and organisational barriers (38\%). These categories or themes were followed by subcategories representing subthemes (see Table 1).

\section{Theme 1. Emotional barriers}

Over two-thirds of the women $(n=20 ; 69 \%)$ of the sample reported experiencing one or more emotions that acted as barriers for disclosing to the health care service. Women stated that they felt 'fear' (59\%), 'embarrassment and shame' (31\%) and 'self-blame' (14\%). Participant 17 highlights this point as she describes how, when wanting to disclose the abuse, she felt "blinded" by her "emotions".

Fear More than half of the women $(n=17 ; 59 \%)$ stated that fear had impacted on their decision to not disclose to the health care service. This fear was divided into three types, 'fear that victims would lose their children', 'fear that a victim's partner would find out', and 'fear that victims would not be believed'.

A third of the women $(n=10 ; 34 \%)$ expressed not disclosing to the health care service as a result of fearing professionals becoming involved and removing their children. 
Table 1 Percentages of participants supporting subthemes of barriers and facilitators for disclosure to health care services

\begin{tabular}{|c|c|c|c|}
\hline \multicolumn{4}{|l|}{ Barriers } \\
\hline Theme & Percentage & Subtheme & Percentage \\
\hline \multirow[t]{3}{*}{ Emotional } & $69 \%$ & Fear & $59 \%$ \\
\hline & & Embarrassed or Ashamed & $31 \%$ \\
\hline & & Self-blame & $14 \%$ \\
\hline \multirow[t]{3}{*}{ Physical } & $38 \%$ & Partner's physical presence & $34 \%$ \\
\hline & & Partner's controlling behaviour & $10 \%$ \\
\hline & & $\begin{array}{l}\text { Partner's manipulation of health } \\
\text { care professionals }\end{array}$ & $3 \%$ \\
\hline \multirow[t]{2}{*}{ Organisational } & $38 \%$ & Not appropriate setting & $24 \%$ \\
\hline & & Not enough time & $14 \%$ \\
\hline \multicolumn{4}{|l|}{ Facilitators } \\
\hline Theme & Percentage & Subtheme & Percentage \\
\hline \multirow[t]{3}{*}{ Interpersonal relations } & $52 \%$ & Listening skills & $38 \%$ \\
\hline & & Trust & $21 \%$ \\
\hline & & Empathy & $10 \%$ \\
\hline \multirow[t]{2}{*}{ Safety } & $28 \%$ & Privacy and confidentiality & $24 \%$ \\
\hline & & Home visits & $7 \%$ \\
\hline Validation & $14 \%$ & Validation & $14 \%$ \\
\hline
\end{tabular}

Responses of some respondents supported multiple subthemes, so percentages under subthemes do not always add up to percentages under main themes
Participant 13 stated her reason for not disclosing was that she was "scared they would take the kids." Participant 14 mentioned that the health care service involving other professionals such as social services, leading to their children being taken away was her "biggest fear" which prevented her from telling her GP.

Over a third of the women $(n=11 ; 38 \%)$ stated their reasons for not disclosing were that they feared that their partner would find out and that the abuse would escalate. Participant 22 stated that her reasons for not disclosing were that she feared that her partner would find out and that this would "cause more trouble than it's worth... resulting in more violence". Participant 1 also confirmed the same fear stating that she was "scared" that her partner would find out if she disclosed, as she would "get it again, like hit."

Two women (7\%) expressed a fear that they would not be believed and so this further acted as a barrier to them disclosing to the health care service. The two women illustrated this: "Concerned about speaking to people because I thought they wouldn't believe me and that was my biggest worry" (Participant 21). "Scared...I'd be made out to be a liar...he used to say they won't believe you" (Participant 5).

Embarrassment and Shame Nearly a third of the women $(n=$ 9; $31 \%$ ) also expressed feeling embarrassment or shame about disclosing abuse to the healthcare service; eight (28\%) communicated that they felt embarrassed, and five (17\%) women reported feeling shame. Participant 7 illustrates how these feelings made it difficult for her to disclose: "I felt dirty, I suppose, and embarrassed...I was ashamed.” Participant 29 also stated that her feelings of being "embarrassed and ashamed" prevented her from disclosing at first to her doctor.

Self-Blame Four women (14\%) mentioned that self-blame further prevented them from disclosing, as they felt that they were to blame for the abuse and were therefore reluctant to disclose. Participant 7 illustrates this as she stated how she had "sometimes thought it was her fault". Participant 2 also demonstrates feeling self-blame: "I remember thinking that I was overreacting and you blame yourself."

\section{Theme 2. Partner-related barriers}

Over a third of the women $(n=11 ; 38 \%)$ also reported perceiving the perpetrator as a physical barrier which prevented them from disclosing. Three sub-categories were identified under this main theme: 'partner's physical presence' (34\%), 'partner's controlling behaviour' (10\%) and 'partner's manipulation of professionals' (3\%).

Partner's Physical Presence A third of the women $(n=10$; $34 \%$ ) felt that they could not disclose as a result of their partner being physically present in appointments. They stated that often their partners would escort them to their appointments and sit in with them making it very difficult for them to disclose. This is highlighted by Participant 19 who describes her experience of visiting the hospital with her partner: "When I went to hospital he came with me. I lied about my cause of 
injury... he was with me the whole time... nurse didn't give me option of going in by myself... all my fingers were cut open ... I said to them I jump started car and car door skimmed off fingers... they never questioned it." Participant 15 also states her disappointment about not being given the opportunity to be seen on her own and this prevented her from disclosing: "When seeing doctor... he came with me... I should be seen on my own... it's impossible when he's sat right there." Finally, Participant 2 further highlights the problem with women not being seen on their own and health care professionals not being sensitive to the fact that some women may not wish for their personal information to be discussed in front of their partners: "Started going into files in front of him... should be asked if it's ok to talk about this".

Partner's Controlling Behaviour The second sub-category identified was that of women feeling that they could not disclose as a result of their partners' controlling behaviour. Women stated that their partners would often make it difficult for them to leave the house to disclose, or would keep a record of where they were and so they found it challenging to seek help. Three women (10\%) had experiences of finding it difficult to leave the house without their partner knowing, which prevented them from disclosing: "Difficult to get out... had to go when he went to work" (Participant 15), "Wasn't allowed to leave the house or go anywhere" (Participant 22).

Partner's Manipulation of Professionals The final subcategory was that of victims feeling that they could not disclose abuse as a result of their partner manipulating professionals who work with the family. One woman (3\%) stated: "He talked himself out of it, even to the pediatrician. He can burst into tears and look pathetic at the switch of a light. One minute he can be crying and then when this person gets out the door he is as hard as nails... manipulative of professionals and even educated professionals such as doctors would be fooled."

\section{Theme 3. Organizational barriers}

Nearly a third of the women $(n=9 ; 31 \%)$ reported experiencing organizational barriers which had prevented them from disclosing to the health care service, namely "appropriateness of setting" (24\%) and "time for disclosure." $(14 \%)$.

Appropriateness of Setting The perceptions that the health care service was not an appropriate place to disclose abuse was held by nearly a quarter of the women $(n=7 ; 24 \%)$. This is demonstrated by Participant 12 who states that domestic violence is a "taboo subject" and how when initially visiting her doctors she "wasn't sure if it was the right place to disclose abuse." Participant 20 further highlights this also as she states her uncertainties of not knowing if the GP surgery is an appropriate place to discuss abuse "not the place or the time to discuss such things... well that's not true, but not much GP can do and didn't think it was the right place to go." In addition to this, Participant 15 stated that they did not feel "comfortable disclosing to GP" and Participant 27 stated "didn't think I could, I wasn't aware of it".

Time for Disclosure Four of the women (14\%) reported that there was not enough time to disclose within the health care setting. Participant 12 illustrates this as she stated that her reasons for not disclosing the abuse to the doctor were that she "didn't think her GP would have time."

\section{Facilitators in Disclosing to the Health Care Service}

Three main categories or themes were identified as facilitators which help women to disclose, namely 'interpersonal relations' (52\%), 'safety' (28\%) and 'validation (14\%)'.

\section{Theme 1. Interpersonal relations}

More than half of the women $(n=15 ; 52 \%$ of the sample) in this study communicated that having a positive relationship with the health care professional made them feel more at ease and able to disclose. Interpersonal relations was divided into three sub-categories: 'listening skills', 'trust' and 'empathy'.

Listening Skills Over a third of the women $(n=11 ; 38 \%)$ expressed that being listened to by their health care professional helped them to disclose. Participants 19 and 28 demonstrate this sub-theme. Participant 19 described how after relocating to flee her partner, her new doctor was not as helpful as her previous doctor as he did not take the time out to listen to her: "this doctor was not good at all... this doctor wants you to come in and go straight back out... don't feel like I can talk to him at all... don't feel like he wants to listen... doctor before listened and was helpful." This therefore illustrates how important it is for victims' disclosure to feel like they are being listened to. Participant 28 further illustrates this as she reflected on her experiences of visiting the GP's surgery and not feeling listened to, she advised that GP's "sit there and listen rather than trying to get you in and out".

Trust Six (21\%) of the women stated that trusting the health care professional helped them with their disclosure. Some of the women reported knowing their doctors for a long time and they stated this helped them when disclosing. Participants 6 and 17 both illustrate this: "He's been my doctor for a long time so I trust him... if someone changed my midwife... I wouldn't be able to talk to new ones... need to build trust... find it hard to open up with new people" (Participant 6). "I 
have known my doctor since I was young, so I trusted him... important that he stayed professional and didn't tell any of my family members" (Participant 17).

Empathy Three women (10\%) also reported that empathy from the health care professional was another important factor which could aid disclosure. For instance, participant 14 stated that when disclosing to her doctor; the doctor had been "empathetic" in his response "trying to understand how I was feeling, which helped." Furthermore, it was shown that victims want to feel understood. Participant 17 highlights this as she stated "I think it's easier talking to people who have actually been through it themselves as they can understand the situation easier... you need a health care professional who will be empathic."

\section{Theme 2. Safety}

Over a quarter of the women $(n=8 ; 28 \%)$ stated that safety was important when disclosing abuse to a health care professional. Within this main category of safety, two sub-categories were present. The first sub-category was that of 'privacy and confidentiality' and the second subcategory was that of 'home visits'.

Privacy and Confidentiality A quarter of the sample ( $n=7$; $24 \%$ ) communicated that privacy and confidentiality were also important factors, which could aid the disclosure of their abuse. Participant 8 illustrates this as she stated when disclosing having "no concerns" as a result of her knowing that the disclosure "was confidential." Further to this Participant 16 illustrates the importance of women being able to disclose safely, she explained "victims need to know that everything is confidential" and she described her experiences in which she "shared the same doctor as her partner" and so she feared the "possibility" that he would "find out" if she disclosed. However, Participant 16 reported that if she had still been in contact with her "midwife" she would have disclosed to her as her midwife only came to visit her in isolation and so she could be sure that the disclosure would be confidential. This suggests that women should be made aware that disclosures will be kept confidential, especially in cases where they may share the same health care professional.

Home Visits Two women (7\%) also communicated that home visits by health care professionals would have been helpful when disclosing as they had not always felt safe leaving the house to attend a meeting in a health care setting. This point is demonstrated by one participant who reported suffering from panic attacks, which prevented her from leaving her home. "I was scared to leave home... doctor won't come out to you... did tell doctor I'm scared of coming out and doctor did not offer a home visit" (Participant 8). In addition to this, Participant 12 also stated that she had felt "too paranoid to go out" and had felt "low". "I was very depressed." This participant described how it was "difficult" for her to "see the doctor" as she could not get past the receptionist "she'll give appointments when she wants to... would have been better for the doctor to come to my house. I would have been able to talk then." Thus, this suggested that disclosures could be increased by women when it is safe to do so being visited in their own home.

\section{Theme 3. Validation}

Four of the women (14\%) reported that the health care professionals validation of abuse was also very important for aiding their disclosures. Participant 11 illustrates this as she states that she had previously "normalised" the abuse. She described how when telling her doctor, the doctor was able to confirm that "emotional abuse was just as bad as physical... he told me it was still abuse." This point was further illustrated by Participant 17 who stated that although she was asked by her midwife if she had been experiencing domestic violence, she had not recognised that emotional abuse could be classified as a form of abuse and so she explained that she tolerated the abuse for some time: "just learnt to live with it... I felt like it was normal as it was more mental abuse." Participant 17 however, stated that she would have benefitted from her midwife educating her and explaining that domestic violence involved other forms of abuse other than just "physical" violence.

Findings from Ethnic Minority Women Other notable findings of this study were that unique barriers were found for disclosure in the ethnic minority women. However, no unique themes were found for the white majority women. Three of the eight ethnic minority women explained that lack of language proficiency hindered them in disclosing. Interestingly, five of the ethnic minority women specifically expressed that prior to telling anyone about the abuse they had turned to religion/prayer first as a way of help-seeking.

\section{Discussion}

The primary aim of this study was to understand the barriers and facilitators faced by women from ethnic majorities and minorities within the UK when disclosing domestic violence to the health care service. Three major themes emerged for barriers of disclosure: 'Emotional barriers', 'Partner-related barriers' and 'Organisational barriers'.

Emotional barriers were most prevalent, with $69 \%$ of the sample stating that they had experienced one or more emotions that had prevented them from disclosing abuse to the 
health care service. This finding aligns with previous research demonstrating that negative emotions, such as fear, embarrassment, and shame, contribute to victims' reasons for not disclosing abuse to the health care service. This has been previously found in other qualitative studies (e.g., Vranda et al. 2018) and also in a large-scale survey of Australian abused women, in which $21 \%$ noted that embarrassment and shame acted as a barrier to them disclosing domestic abuse to their GP (Hegarty and Taft 2001). In light of these findings, health care professionals - when disclosed to - should convey that they believe victims, reassure them and acknowledge that their decision to disclose was likely to have been 'difficult' and 'frightening'. To reduce embarrassment and shame it is further recommended that health care professionals respond empathically and non-judgmentally to (potential) victims and they should undergo specialized training, which would prepare them for this. It should be noted though that attempts to introduce domestic violence specific training into the curricula of professional programs have been challenging, due to staff resistance (Valpied et al. 2017). An alternative may be to offer an option to disclose via the computer, which may be preferred for victims who feel embarrassed or ashamed (Chang et al. 2012).

Partner-related barriers for disclosure included partners' controlling behaviours; victims' partners would prevent them from leaving the house or insist on attending appointments. This finding was corroborated in another qualitative study in the UK, whereby domestic violence victims reported that their partners' made it difficult for them to disclose, as they would attend their appointments with them (Rose et al. 2011). Uniquely, one person in our study reported that the perpetrator emotionally manipulated healthcare staff, which further reduced the chance of the victim disclosing. It is important that professionals are educated about the perpetrators ways of preventing disclosure. Whenever possible, women should be seen alone.

Two 'organisational barriers' were identified. Women communicated concerns about there not being sufficient time to disclose abuse and were also worried that the health care setting would not be an appropriate environment to discuss abuse. This finding corroborated results from Narula, Agarwal and McCarthy's (Narula et al. 2012) qualitative research among Canadian abuse victims. Women in their study felt that it was inappropriate to disclose abuse to the family doctors. By contrast, $97 \%$ of women in this study stated that they felt that all women should be routinely asked by their GP if they are experiencing domestic abuse. To tackle this issue, WHO (2002) emphasise the importance of increasing knowledge among health service professionals and clients that domestic abuse is a medical problem.

This knowledge can be gained using multiple methods. First, health care professionals should make an effort to display information on the topic. In our study only (45\%) of the women felt that there were 'enough' leaflets displayed in GPs' surgeries. In line with this idea, Bolin and Elliott (1996) demonstrated the importance of providing information to patients' as this increased their disclosure. In their study, two groups of doctor's attended training for how to respond to domestic violence disclosures. The first group of doctors were assigned to wear buttons that read, "It's okay to talk to me about family violence and abuse" and the other group of doctors wore no button. The doctors who wore the button managed to elicit significantly more conversations about abuse, despite them both having the same training and the doctors who wore the buttons also had an increase in patients' disclosures. These results highlight the importance of environmental cues and ensuring that victims are made to feel comfortable to disclose. Second, health care professionals should ideally receive training to understand the impact of domestic violence on health and to train them to proactively ask about domestic violence. This is not yet standard practice, but could play a key role in improving disclosure as victims need to be given the opportunity to initiate support (Kataoka and Imazeki 2018). A recent study by Baird et al. (2018) found that a brief training (1day workshop) improved the knowledge and preparedness of midwives and nurses to conduct routine enquiry and respond to women's disclosures of domestic abuse. Such training may be even more effective if health care professionals can observe and model good practice. Engaging in case analysis, role play, obtaining feedback and having in-depth discussions, whilst making the training experiential and interactive has been found to be particularly effective in previous studies with health care professionals (Torres Vitolas et al. 2010).

Facilitators of disclosure in the health care service identified in this study fell under three major themes: 'interpersonal relations, 'safety' and 'validation'. The theme category of 'interpersonal relations' arose as a result of 52\% victims in this study stating that they were able to disclose if they trusted the health professional. This corroborated other research, indicating that trust aided domestic violence disclosure to health care professionals (Eddy et al. 2008). One way of health care professionals establishing trust is for them to provide follow-up appointments with their patients, as continuity of care may help victims to gain more trust and is likely to facilitate later disclosure (Narula et al. 2012). This is particularly important since studies in the past have found that health care professionals have had difficulty establishing rapport with victims and they have noted that this has been a barrier to the disclosure process (Williams et al. 2017).

Over a quarter $(28 \%)$ of female victims in this study suggested that safety and confidentiality was key in helping victims to disclose. Additionally, two women in this study expressed the need for health care professionals to provide home visits. Home visits may be an effective way to reach victims who feel too scared to present to health care service (Davidov et al. 2018). However, it is accompanied by safety 
concerns which need to be taken into account (Eddy et al. 2008). Telehealth services could offer another solution as it allows victims to access support from their own homes. This may be particularly useful for victims whose partners control their physical whereabouts. A recent qualitative study showed preliminary evidence that online interventions can be an effective way to reach out to domestic violence victims (Tarzia et al. 2018).

Furthermore, $14 \%$ of victims in this study communicated valuing health care professionals who validated their abuse experiences. Reisenhofer and Seibold (2013) similarly found in an Australian sample that victims in their study valued validation from the health care professional, as this helped them to understand that they were being abused and also the seriousness of their abuse. Notably, some of our participants particularly appreciated it when a health care professional confirmed that emotional abuse is also abuse. These findings suggest that health care professionals should be trained to validate victims' experiences, especially when these victims disclose non-physical forms of abuse. It is also recommended as part of training health care professionals that personal attitudes are reflected upon with regard to the different types of abuse, and to ensure that they recognize that all forms are unacceptable.

Finally, this study also highlighted some additional problems for black and ethnic minority victims as they sometimes experienced communication and language difficulties. This finding is in line with existing research in a systematic review of four qualitative studies in the UK, which found language and interpretation also acted as barriers to disclosure in ethnic minority victims (Femi-Ajao et al. 2020). Possibly, in our study the barriers of language and communication may have resulted in the majority (five) of the eight ethnic minority women turning to religion first. This has not yet been found in other studies with ethnic minority domestic violence victims. However, in another study with sexual assault victims, ethnic minority women, specifically African American victims of sexual violence, were found to use religious coping more than other ethnicities (Ahrens et al. 2010). Additionally, it has been observed in other studies with ethnic minority victims of domestic violence in the UK, that collaboration with faith-based organizations is key to aiding disclosure (Femi-Ajao 2018). Therefore, it would be interesting to research further the problems and barriers which ethnic minority women may experience when disclosing domestic abuse and how different cultures may deal with disclosure differently. It could be that interventions with domestic violence for ethnic minority women may be better implemented in religious organizations. In some cases, the provision of language support and interpreters with knowledge of the associated culture (link workers) may further help disclosure from ethnic minority victims to professionals (Reina et al. 2014).

This study had a number of limitations. First, it was conducted among adult female victims of domestic violence in only one geographical area of the UK. Future research is required to explore victims' views on barriers and facilitators of disclosure in other areas of the UK, and in other countries, to see if the themes identified in this study generalize to other populations. Second, this study included women who had already disclosed domestic violence (although not necessarily always to the health care service). Therefore, it is possible that the barriers and facilitators experienced by the women in this study are different to those experienced by victims who do not disclose. Third, whilst the qualitative method of interviewing was useful in gaining in-depth information, it is susceptible to social desirability bias. For example, women may have provided answers to the researcher, which were not totally accurate due to wanting to please the researcher by telling them what they perceived the researcher wanted to hear. Future research may include larger scale quantitative studies, which may be less susceptible to such biases. Relatedly, the percentages of women indicating experiencing certain barriers or facilitators may differ if questionnaires specifying potential barriers and facilitators were used, and should thus be interpreted with caution. An additional limitation of this research was that it grouped together all health care professionals and so it did not explore if there were differences between disclosing to a GP versus a health visitor for instance, as has been researched in previous studies (Bacchus et al. 2002).

Notwithstanding these limitations, this qualitative study contributed to the literature on domestic violence by further elucidating the complex set of barriers and facilitators experienced by British female domestic violence victims when disclosing abuse to health care professionals. This study also highlighted some problems of ethnic minority victims of domestic violence that require further research. This study thereby contributes to the knowledge base that is needed for health care services to become better equipped to facilitate disclosure by domestic violence victims, helping more women to access support and become free from victimization.

Supplementary Information The online version contains supplementary material available at https://doi.org/10.1007/s10896-020-00236-3.

\section{Compliance with Ethical Standards}

Conflict of Interest The authors declare no conflicts of interest.

Open Access This article is licensed under a Creative Commons Attribution 4.0 International License, which permits use, sharing, adaptation, distribution and reproduction in any medium or format, as long as you give appropriate credit to the original author(s) and the source, provide a link to the Creative Commons licence, and indicate if changes were made. The images or other third party material in this article are included in the article's Creative Commons licence, unless indicated otherwise in a credit line to the material. If material is not included in the article's Creative Commons licence and your intended use is not permitted by statutory regulation or exceeds the permitted use, you will need to obtain permission directly from the copyright holder. To view a copy of this licence, visit http://creativecommons.org/licenses/by/4.0/. 


\section{References}

Ahrens, C. E., Abeling, S., Ahmad, S., \& Hinman, J. (2010). Spirituality and well-being: The relationship between religious coping and recovery from sexual assault. Journal of Interpersonal Violence, 25, $1242-1263$

Ayres, L. (2007). Qualitative research proposals-part V: Rigor in data analysis. Journal of Wound, Ostomy, and Continence Nursing, 34, 489-491.

Bacchus, L., Mezey, G., \& Bewley, S. (2002). Women's perceptions and experiences of routine screening for domestic violence in a maternity service. British Journal of Obstetrics and Gynaecology, 109, 9 16.

Baird, K., Saito, A., Eustace, J., \& Creedy, D. (2018). Effectiveness of training to promote routine enquiry for domestic violence by midwives and nurses: A pre-post evaluation study. Women and Birth, 31, 285-291.

Berg, B. (2004). Qualitative research methods for the social sciences (5th ed.). New York: Pearson Education.

Bolin, L., \& Elliott, B. (1996). Physician detection of family violence. Do buttons worn by doctors generate conversations about domestic abuse? Minnesota Medicine, 79, 42-55.

Bowling, A. (1997). Research methods in health. Investigating health and health services. Buckingham: Open University Press.

Bradbury-Jones, C., \& Broadhurst, K. (2015). Are we failing to prepare nursing and midwifery students to deal with domestic abuse? Findings from a qualitative study. Journal of Advanced Nursing, $71,2062-2072$.

Canadian Council for Refugees. (2016). How immigration status can affect women in situations of violence or abuse. Retrieved, January 30, 2020 from: www.ccrweb.ca/en/how-immigrationstatus-can-affect-womensituations-violence

Chang, J. C., Dado, D., Schussler, S., Hawker, L., Holland, C., Burke, J. G., \& Cluss, P. A. (2012). In person versus computer screening for intimate partner violence among pregnant patients. Patient Education and Counseling, 88, 443-448.

Chapman, A., \& Monk, C. (2015). Domestic violence awareness. American Journal of Psychiatry, 172, 944-945.

Chibber, K., Cantor, J., \& Greenberg, E. (2016). Domestic violence literature review: Analysis report. Boston, MA: JSI Research and Training Institute.

Correa, N. P., Cain, C. M., Bertenthal, M., \& Lopez, K. K. (2020). Women's experiences of being screened for intimate partner violence in the health care setting. Nursing for Women's Health, 24, 185-196.

Davidov, D. M., Coffman, J., Dyer, A., Bias, T. K., Kristjansson, A. L., Mann, M. J., \& Abildso, C. G. (2018). Assessment and response to intimate partner violence in home visitation: A qualitative needs assessment with home visitors in a statewide program. Journal of Interpersonal Violence, 088626051875486.

Department of Health. (2017). Domestic abuse: A resource for health professionals. London: Department of Health.

Eddy, T., Kilburn, E., \& Chang, C. (2008). Facilitators and barriers for implementing home visit interventions to address intimate partner violence: Town and gown partnerships. Nursing Clinics of North America, 43, 419-435.

Evans, M. A., \& Feder, G. S. (2014). Help-seeking amongst women survivors of domestic violence: A qualitative study of pathways towards formal and informal support. Health Expectations, 19, $62-73$.

Feder, G., Ramsay, J., Dunne, D., Rose, M., Arsene, C., Norman, R., Kuntze, S., Spencer, A., Bacchus, L., Hague, G., Warburton, A., \& Taket, A. (2009). How far does screening women for domestic (partner) violence in different health-care settings meet criteria for a screening programme? Systematic reviews of nine UK, National
Screening Committee criteria. Health Technology Assessment, 13, 137-347.

Femi-Ajao, O. (2018). Intimate partner violence and abuse against Nigerian women resident in England, UK: A cross-sectional qualitative study. BMC Women's Health, 18, 123.

Femi-Ajao, O., Kendal, S., \& Lovell, K. (2020). A qualitative systematic review of published work on disclosure and help-seeking for domestic violence and abuse among women from ethnic minority populations in the UK. Ethnicity \& Health, 25, 732-746.

Follingstad, D. R., Rogers, M. J., \& Duvall, J. L. (2012). Factors predicting relationship satisfaction, investment, and commitment when women report high prevalence of psychological abuse. Journal of Family Violence, 27, 257-273.

Garcia-Moreno, C. P., Pallitto, C., Devries, K., \& Töckl, H. (2013). Global and regional estimates of violence against women: Prevalence and health effects of intimate partner violence and non-partner sexual violence. Geneva: World Health Organization Press.

García-Moreno, C., Hegarty, K., d'Oliveira, A., Koziol-McLain, J., Colombini, M., \& Feder, G. (2015). The health systems response to violence against women. The Lancet, 385, 1567-1579.

Graneheim, U. H., \& Lundman, B. (2004). Qualitative content analysis in nursing research: Concepts, procedures and measures to achieve trustworthiness. Nurse Education Today, 24, 105-112.

Grbich, C. (2007). Qualitative data analysis: An introduction. London: Sage publications.

Hegarty, K., \& Taft, A. (2001). Overcoming barriers to disclosure and inquiry of partner abuse for women attending general practice. Australian and New Zealand Journal of Public Health, 25, 433437.

Hester, M., Ferrari, G., Jones, S., Williamson, E., Peters, T. J., Bacchus, L., \& Feder, G. S. (2015). Occurrence and impact of negative behaviour, including domestic violence and abuse, in men attending UK primary care health clinics: A cross-sectional survey. BMJ Open, 5, 1-10.

Hinsliff-Smith, K., \& McGarry, J. (2017). Understanding management and support for domestic violence and abuse within emergency departments: A systematic literature review from 2000-2015. Journal of Clinical Nursing, 26, 4013-4027.

Home Office. (2012) Cross-government definition of domestic violenceA consultation. Summary of responses. Available at: https:/www. gov.uk/government/uploads/system/uploads/attachment_data/file/ 157800/domestic-violence-definition.pdf ().

Kataoka, Y., \& Imazeki, M. (2018). Experiences of being screened for intimate partner violence during pregnancy: A qualitative study of women in Japan. BMC Women's Health, 18, 75.

Katiti, V., Sigalla, G. N., Rogathi, J., Manongi, R., \& Mushi, D. (2016). Factors influencing disclosure among women experiencing intimate partner violence during pregnancy in Moshi municipality, Tanzania. BMC Public Health, 16, 715.

Keeling, J., \& Fisher, C. (2015). Health professionals' responses to women's disclosure of domestic violence. Journal of Interpersonal Violence, 30, 2363-2378.

Knodel, J. (1993). The design and analysis of focus group studies: A practical approach. In D. Morgan (Ed.), Successful focus groups: Advancing the state of the art (pp. 35-50). Thousand Oaks: Sage.

Lacey, K. K., McPherson, M. D., Samuel, P. S., Powel Sears, K., \& Head, D. (2013). The impact of different types of intimate partner violence on the mental and physical health of women in different ethnic groups. Journal of Interpersonal Violence, 28, 359-385.

McFarlane, J., Symes, L., Maddoux, J., Gilroy, H., \& Koci, A. (2014). Is length of shelter stay and receipt of a protection order associated with less violence and better functioning for abused women? Outcome data 4 months after receiving services. Journal of Interpersonal Violence, 29, 2748-2774. 
McGarry, J. (2016). Domestic violence and abuse: An exploration and evaluation of a domestic abuse nurse specialist role in acute health care services. Journal of Clinical Nursing, 26, 2266-2273.

McGarry, J., \& Nairn, S. (2015). An exploration of the perceptions of emergency department nursing staff towards the role of a domestic abuse nurse specialist: A qualitative study. International Emergency Nursing, 23, 65-70.

Narula, A., Agarwal, G., \& McCarthy, L. (2012). Intimate partner violence: Patients' experiences and perceptions in family practice. Family Practice-The International Journal for Research in Primary Care, 29, 593-600.

National Institute for Health and Care Excellence. (2014). Domestic violence and abuse: How health services, social care and the organisations they work with can respond effectively. Report No, 50 Retrieved from: https://www.nice.org.uk/Guidance/PH50.

Othman, S., Goddard, C. R., \& Piterman, L. (2014). Victims' barriers to discussing domestic violence in clinical consultations: A qualitative enquiry. Journal of Interpersonal Violence, 29, 1497-1513.

Polit, D. F., \& Beck, C. T. (2010). Essentials of nursing research: Appraising evidence for nursing practice (7th ed.). Philadelphia: Lippincott Williams, \& Wilkins.

Ramsay, J., Rutterford, C., Gregory, A., Dunne, D., Eldridge, S., Sharp, D., \& Feder, G. (2012). Domestic violence: Knowledge, attitudes and clinical practice of selected UK primary healthcare clinicians. British Journal of General Practice, 62, e647-e655.

Reina, A. S., Lohman, B. J., \& Maldonado, M. M. (2014). "He said they'd deport me": Factors influencing domestic violence helpseeking practices among Latina immigrants. Journal of Interpersonal Violence., 29, 593-615.

Reisenhofer, S., \& Seibold, C. (2013). Supporting the victims of violence emergency healthcare experience of women living with intimate partner violence. Journal of Clinical Nursing, 22, 2253-2263.

Rimmer, A. (2017). Domestic violence is poorly covered in medical training, study finds. British Medical Journal, 359, j4646.

Rivara, F. P., Anderson, M. L., Fishman, P., Bonomi, A. E., Reid, R. J., Carrell, D., \& Thompson, R. S. (2007). Intimate partner violence and health care costs and utilization for children living in the home. Pediatrics, 120, 1270-1277.

Rivielo, R. J. (2010). Manual of forensic emergency medicine: A guide for clinicians. Sudbury: Jones \& Bartlett Publishers.

Rose, D., Trevillion, K., Woodall, A., Morgan, C., Feder, G., \& Howard, L. (2011). Barriers and facilitators of disclosures of domestic violence by mental health service users: Qualitative study. The British Journal of Psychiatry, 198, 189-194.

Rubin, H., \& Rubin, I. (1995). Qualitative interviewing: The art of hearing data. Thousand Oaks: Sage Publications.

Salmon, D., Baird, K., \& White, P. (2015). Women's views and experiences of antenatal enquiry for domestic abuse during pregnancy. Health Expectations, 18, 867-878.

Shanko, W., Wolday, M., Assefa, N., \& Aro, A.R (2013). Domestic violence against women in Kersa, Oromia region, eastern Ethiopia. Eastern Mediteranean Health Journal. 19, 18-23.

Spangaro, J., Herring, S., Koziol-Mclain, J., Rutherford, A., Frail, M. A., \& Zwi, A. B. (2016a). 'They aren't really black fellas but they are easy to talk to': Factors which influence Australian aboriginal women's decision to disclose intimate partner violence during pregnancy. Midwifery, 41, 79-88.

Spangaro, J., Koziol-McLain, J., Zwi, A., Rutherford, A., Frail, M. A., \& Ruane, J. (2016b). Deciding to tell: Qualitative configurational analysis of decisions to disclose experience of intimate partner violence in antenatal care. Social Science \& Medicine, 154, 45-53.

Sprague, S., McKay, P., Madden, K., Scott, T., Tikasz, D., Sloboghean, G., \& Bandhari, M. (2017). Outcome measures for evaluating intimate partner violence programs within clinical settings: A systematic review of the literature. Trauma, Violence \& Abuse, 18, 508522.

Sundborg, E., Törnkvist, L., Saleh-Stattin, N., Wändell, P., \& Hylander, I. (2017). To ask, or not to ask: The hesitation process described by district nurses encountering women exposed to intimate partner violence. Journal of Clinical Nursing, 26, 2256-2265.

Tarzia, L., Cornelio, R., Forsdike, K., \& Hegarty, K. (2018). Women's experiences receiving support online for intimate partner violence: How does it compare to face-to-face support from a health professional? Interacting with Computers, 30, 433-443.

Taylor, J., Bradbury-Jones, C., Kroll, T., \& Duncan, F. (2013). Health professionals' beliefs about domestic abuse and the issue of disclosure: A critical incident technique study. Health and Social Care in the Community, 21, 489-499.

Torres Vitolas, C., Bacchu, L., \& Aston, G. (2010). A comparison of the training needs of maternity and sexual health professionals in a London teaching hospital with regards to routine enquiry for domestic abuse. Public Health, 124, 472-478.

Trevillion, K., Hughes, B., Feder, G., Borschmann, R., Oram, S., \& Howard, L. M. (2014). Disclosure of domestic violence in mental health settings: A qualitative meta-synthesis. International Review on Psychiatry, 26, 430-444.

Valpied, J., Aprico, K., Clewett, J., \& Hegarty, K. (2017). Are future doctors taught to respond to intimate partner violence? A study of Australian medical schools. Journal of Interpersonal Violence, 32, 2419-2432.

Vranda, M. N., Kumar, C. N., Muralidhar, D., Janardhana, N., \& Sivakumar, P. T. (2018). Barriers to disclosure of intimate partner violence among female patients availing services at tertiary care psychiatric hospitals: A qualitative study. Journal of Neurosciences in Rural Practice, 9, 326-330.

Walby, S., Towers, J., \& Francis, B. (2015). Is violent crime increasing or decreasing? A new methodology to measure repeat attacks making visible the significance of gender and domestic relations. British Journal of Criminology, 56, 1203-1234.

Williams, J. R., Halstead, V., Salani, D., \& Koermer, N. (2017). An exploration of screening protocols for intimate partner violence in healthcare facilities: A qualitative study. Journal of Clinical Nursing., 26, 2192-2201.

World Health Organisation. (2013). Global and regional estimates of violence against women: Prevalence and health effects of intimate partner violence and non- partner sexual violence. Geneva: WHO Retrieved from: http://apps.who.int/iris/bitstream/10665/85239/1/ 9789241564625 eng.pdf?ua $=1$.

World Health Organization. (1999). Report of the consultation on child abuse prevention. Geneva: WHO Retrieved from: http://www.who. int/iris/handle/10665/65900.

World Health Organization. (2002). World report on violence and health. Geneva: WHO Retrieved from: https://apps.who.int/iris/bitstream/ handle/10665/42495/9241545615 eng.pdf?sequence=1.

Publisher's Note Springer Nature remains neutral with regard to jurisdictional claims in published maps and institutional affiliations. 